\title{
CpG Island Chromatin Is Shaped by Recruitment of ZF-CxxC Proteins
}

\author{
Neil P. Blackledge ${ }^{1}$, John P. Thomson², and Peter J. Skene ${ }^{3}$ \\ ${ }^{1}$ Department of Biochemistry, University of Oxford, Oxford OX1 3QU, United Kingdom; ${ }^{2}$ MRC Human Genetics Unit at the \\ Institute of Genetics and Molecular Medicine, University of Edinburgh, Edinburgh EH4 2XU, United Kingdom; ${ }^{3}$ Fred \\ Hutchinson Cancer Research Center, Seattle, Washington 98109 \\ Correspondence: neil.blackledge@bioch.ox.ac.uk
}

\begin{abstract}
Most mammalian gene promoters are embedded within genomic regions called $\mathrm{CpG}$ islands, characterized by elevated levels of nonmethylated $\mathrm{CpG}$ dinucleotides. Here, we describe recent work demonstrating that $\mathrm{CpG}$ islands act as specific nucleation sites for the zinc finger $\mathrm{CxxC}$ domain-containing proteins CFP1 and KDM2A. Importantly, both CFP1 and KDM2A are associated with enzymatic activities that modulate specific histone lysine methylation marks. The action of these zinc finger $\mathrm{CxxC}$ domain proteins therefore imposes a defined chromatin architecture on $\mathrm{CpG}$ islands that distinguishes these important regulatory elements from the surrounding genome. The functional consequence of this $\mathrm{CpG}$ island-directed chromatin environment is discussed.
\end{abstract}

Approximately two-thirds of mammalian gene promoters are found within genomic regions known as $\mathrm{CpG}$ islands (CGIs). In contrast to bulk genomic DNA in which $\mathrm{CpG}$ dinucleotides are underrepresented and pervasively methylated, CGIs show a high density of CpGs and are refractory to DNA methylation. Despite more than 25 years of work aimed at understanding CGI function, it remains unclear how they contribute to the activity of gene promoters. However, of notable progress in the past few years is our demonstration that CGIs, through specific recruitment of proteins that bind nonmethylated DNA, can specifically alter the local chromatin environment of gene regulatory elements (Blackledge et al. 2010; Thomson et al. 2010).

We know that methylated CpGs act as nucleation sites for methyl-CpG binding domain (MBD) proteins that are generally associated with transcriptional repression. Based on the existence of MBD proteins, Skalnik and colleagues hypothesized that proteins may exist that specifically recognize nonmethylated CpGs. Through subsequent work, they identified the $\mathrm{CpG}$ binding protein (CGBP), later named $\mathrm{CxxC}$ finger protein 1 (CFP1), as such a factor (Voo et al. 2000). Importantly, this protein was found to bind to DNA through a ZF (zinc finger)-CxxC domain that specifically recognizes $\mathrm{CpG}$ dinucleotides in vitro.

The question remained: Does CFP1 recognize nonmethylated CGIs in vivo and thus impact on CGI function? This possibility was particularly intriguing, as CFP1 forms part of an extended family of ZF-CxxC domain-containing proteins that include chromatin-binding factors such as DNMT1, MLL1, and MBD1. With the emergence of massively parallel sequencing technologies coupled to chromatin immunoprecipitation (ChIP-seq), an exciting opportunity was presented to formally test the relationship between ZF-CxxC proteins and CGIs. To address this possibility, we performed independent studies, focusing on the ZF-CxxC proteins CFP1 and histone lysine demethylase 2A (KDM2A, also referred to as JHDM1a, FBXL11, or CXXC8). This unbiased approach showed a remarkable genome-wide association between sites of enrichment for both of these proteins and nonmethylated CGIs (Fig. 1A) (Blackledge et al. 2010; Thomson et al. 2010). Therefore, at least in the case of CFP1 and KDM2A, the ZF-CxxC domain appears to act as a CGI-targeting module. Significantly, these studies showed for the first time that CGIs are directly interpreted through recognition of nonmeth-

Editors: C. David Allis, Marie-Laure Caparros, Thomas Jenuwein, and Danny Reinberg

Additional Perspectives on Epigenetics available at www.cshperspectives.org

Copyright (C 2013 Cold Spring Harbor Laboratory Press; all rights reserved; doi: 10.1101/cshperspect.a018648

Cite as Cold Spring Harb Perspect Biol 2013;5:a018648 
N.P. Blackledge et al.

A

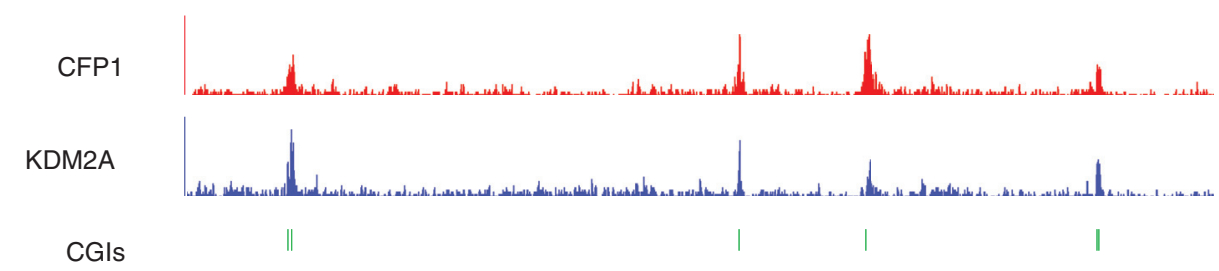

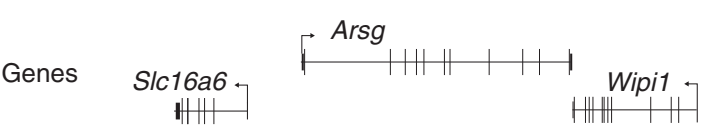
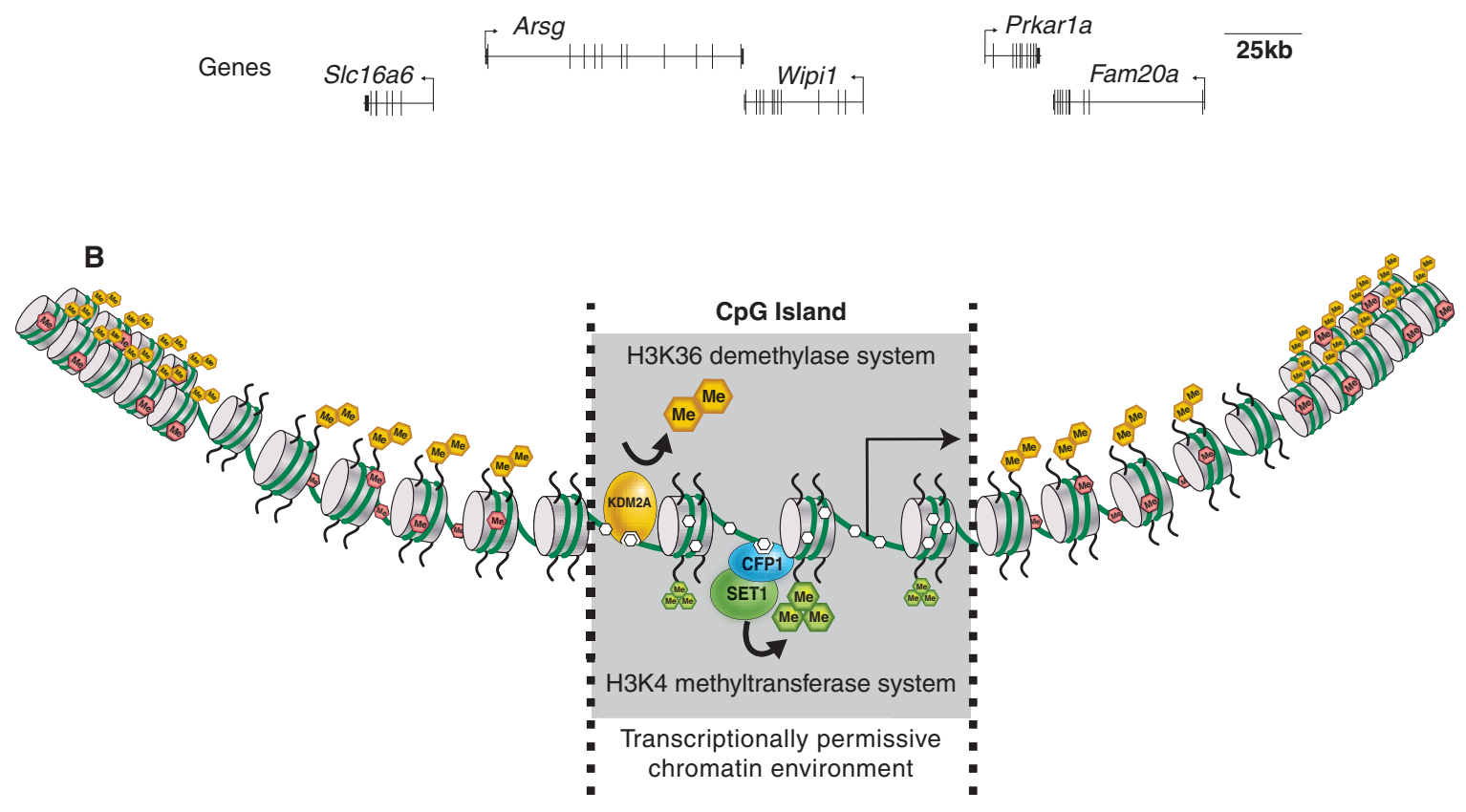

unmethylated C

Me $5 \mathrm{mC}$

Me $\mathrm{H} 3 \mathrm{KK} 36 \mathrm{me} 2$

$\mathrm{H} 3 \mathrm{~K} 4 \mathrm{me} 3$

Figure 1. ZF-CxxC proteins at CpG islands. (A) CFP1 (top panel, red) and KDM2A (bottom panel, blue) ChIP-seq analysis for an $\sim 300 \mathrm{~kb}$ region of mouse chromosome 11 (data from Blackledge et al. 2010 and Thomson et al. 2010). Annotated genes and CGIs (green bars) are illustrated below the sequence traces. (B) CFP1 and KDM2A impose a specific chromatin environment at CGIs that is distinct from the rest of the genome.

ylated DNA, and that most, if not all, nonmethylated CGIs share common protein factors.

Interestingly, and of potential relevance to CGI function, most ZF-CxxC proteins are associated with chromatin-modifying activities. For example, CFP1 exists in a SETD1-containing methyltransferase complex that acts on the histone $\mathrm{H} 3$ lysine 4 (H3K4) residue, whereas KDM2A is a JmjC domain-containing demethylase enzyme that targets the histone $\mathrm{H} 3$ lysine 36 (H3K36) residue. In our studies, we observed that the histone-modifying activities associated with these ZF-CxxC proteins impose a defined chromatin environment at CGIs. Specifically, the action of CFP1 facilitates nucleation of histone H3K4 trimethylation (H3K4me3), a punctate mark generally associated with $5^{\prime}$ ends of genes, whereas KDM2A depletes H3K36 dimethylation (H3K36me2), a very abundant and broadly distributed modification adorning $30 \%-50 \%$ of total histone H3 (Blackledge et al. 2010; Thomson et al. 2010).

A surprising finding from these studies was that CFP1 and KDM2A bind at CGIs and modify CGI chromatin independently of transcriptional activity. A striking illustration of this was the demonstration that an exogenous CpG-rich sequence is sufficient to recruit CFP1 and nucleate H3K4me3 without concomitant recruitment of RNA polymerase II (RNA Pol II; Thomson et al. 2010). These bodies of work have therefore established a new paradigm, whereby the underlying DNA signal at CGIs (i.e., a high density of nonmethylated CpGs) is translated into a defined histone modification status (i.e., $\mathrm{H} 3 \mathrm{~K} 4 \mathrm{me} 3$ enriched and H3K36me2 depleted). Therefore, via the ZF-CxxC system, nonmethylated CGIs have a "hard-wired" chromatin environment distinct from the rest of the genome (Fig. 1B). 
The above studies prompted the question, within the context of CGI elements, what is the functional significance of ZF-CxxC protein binding and the chromatin modification states that they impose? Histone lysine methylation marks are thought to influence transcription by recruiting specific effector proteins via plant homeodomain (PHD) fingers or chromatin-modifier (chromo-) domains. In the case of $\mathrm{H} 3 \mathrm{~K} 4 \mathrm{me} 3$, a number of studies suggest that this mark has the potential to recruit PHD finger proteins that support transcription, such as the core transcription factor TFIID, the NuRF chromatin remodeling complex, and ING4-containing histone acetyltransferase complexes. In contrast, studies in yeast suggest that $\mathrm{H} 3 \mathrm{~K} 36 \mathrm{me} 2$ may repress transcription initiation by recruiting the chromodomain protein EAF3, a component of the RPD3S histone deacetylase complex. It is therefore possible that the combined effect of H3K4me3 enrichment and H3K36me2 depletion at CGIs creates a permissive chromatin environment that favors transcriptional initiation.

CGI promoters show a number of unique characteristics that may be attributable, at least in part, to the permissive chromatin environment created by ZF-CxxC proteins. For example, unlike classical TATA-box promoters, which use a defined transcriptional start point, CGI promoters tend to initiate transcription over a broad region of $100 \mathrm{bp}$ or more. Furthermore, even in the absence of productive transcription, CGI promoters are enriched for RNA Pol II and show short, nonproductive, bidirectional transcripts (Core et al. 2008). Finally, inducible "primary response genes" that have CGI promoters can be rapidly activated by lipopolysaccharide stimulation without a requirement for chromatin-remodeling events (Ramirez-Carrozzi et al. 2009; illustrated in Fig. 9 of Busslinger and Tarakhovsky 2014). This is in contrast to primary response genes with non-CGI promoters for which productive transcriptional output requires SWI/SNF-mediated chromatin remodeling. Further studies are required to determine whether ZFCxxC proteins contribute to some or all of these CGI characteristics and ultimately to define the precise role that ZFCxxC proteins play in CGI function.

As a final thought, it should be emphasized that protection from DNA methylation is at the crux of CGI existence, and is essential for ZF-CxxC protein nucleation at these regions. Although the mechanisms responsible for establishing and maintaining this DNA methylation-free state are poorly defined, one alluring possibility is that ZF-CxxC proteins themselves may contribute. For example, in vitro studies suggest that $\mathrm{H} 3 \mathrm{~K} 4 \mathrm{me} 3$, the mark placed by the CFP1 complex, may block de novo DNA methylation, exemplified by the inhibitory effect this mark has on DNMT3L binding, which is part of the DNMT3A/3L de novo methylating complex (described in Cheng 2014). Also, the ZF-CxxC protein TET1 is a hydroxylase enzyme able to convert methylcytosine into hydroxymethylcytosine, a reaction that has been implicated in DNA demethylation pathways (described in $\mathrm{Li}$ and Zhang 2014). It is therefore tempting to speculate that at CGIs, ZF-CxxC proteins provide a self-reinforcing loop of nonmethylated CpG recognition and subsequent protection from DNA methylation.

\section{REFERENCES}

* Reference is also in this collection.

Blackledge NP, Zhou JC, Tolstorukov MY, Farcas AM, Park PJ, Klose RJ. 2010. CpG islands recruit a histone $\mathrm{H} 3$ lysine 36 demethylase. Mol Cell 38: $179-190$

* Busslinger M, Tarakhovsky A. 2014. Epigenetic control of immunity. Cold Spring Harb Perspect Biol doi: 10.1101/cshperspect.a019307.

* Cheng X. 2014. Structural and functional coordination of DNA and histone methylation chromatin. Cold Spring Harb Perspect Biol doi: 10.1101/cshperspect.a018747.

Core LJ, Waterfall JJ, Lis JT. 2008. Nascent RNA sequencing reveals widespread pausing and divergent initiation at human promoters. Science 322: $1845-1848$.

* Li E, Zhang Y. 2014. DNA methylation in mammals. Cold Spring Harb Perspect Biol doi: 10.1101/cshperspect.a019133.

Ramirez-Carrozzi VR, Braas D, Bhatt DM, Cheng CS, Hong C, Doty KR, Black JC, Hoffmann A, Carey M, Smale ST. 2009. A unifying model for the selective regulation of inducible transcription by $\mathrm{CpG}$ islands and nucleosome remodeling. Cell 138: 114-128.

Thomson JP, Skene PJ, Selfridge J, Clouaire T, Guy J, Webb S, Kerr AR, Deaton A, Andrews R, James KD, et al. 2010. CpG islands influence chromatin structure via the CpG-binding protein Cfp1. Nature 464: $1082-1086$.

Voo KS, Carlone DL, Jacobsen BM, Flodin A, Skalnik DG. 2000. Cloning of a mammalian transcriptional activator that binds unmethylated CpG motifs and shares a CXXC domain with DNA methyltransferase, human trithorax, and methyl-CpG binding domain protein $1 . \mathrm{Mol}$ Cell Biol 20: 2108-2121. 


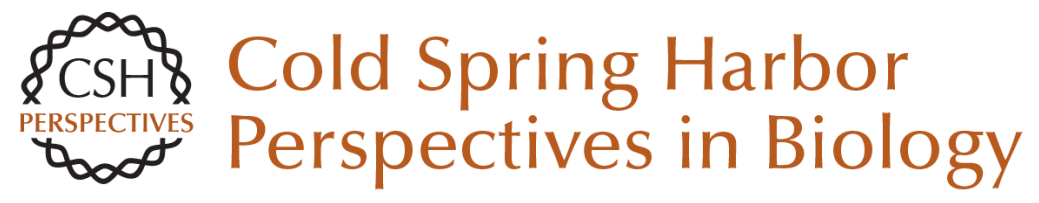

\section{CpG Island Chromatin Is Shaped by Recruitment of ZF-CxxC Proteins}

Neil P. Blackledge, John P. Thomson and Peter J. Skene

Cold Spring Harb Perspect Biol 2013; doi: 10.1101/cshperspect.a018648

\section{Subject Collection Epigenetics}

Metabolic Signaling to Chromatin Shelley L. Berger and Paolo Sassone-Corsi

Histone and DNA Modifications as Regulators of Neuronal Development and Function Stavros Lomvardas and Tom Maniatis

Histone Modifications and Cancer James E. Audia and Robert M. Campbell

Epigenetics and Human Disease Huda Y. Zoghbi and Arthur L. Beaudet

Induced Pluripotency and Epigenetic Reprogramming Konrad Hochedlinger and Rudolf Jaenisch

Long-Range Chromatin Interactions Job Dekker and Tom Misteli

RNAi and Heterochromatin Assembly Robert Martienssen and Danesh Moazed

Dosage Compensation in Drosophila John C. Lucchesi and Mitzi I. Kuroda
Epigenetic Determinants of Cancer Stephen B. Baylin and Peter A. Jones

Maintenance of Epigenetic Information Geneviève Almouzni and Howard Cedar

A Structural Perspective on Readout of Epigenetic Histone and DNA Methylation Marks Dinshaw J. Patel

The Necessity of Chromatin: A View in

Perspective Vincenzo Pirrotta

Germline and Pluripotent Stem Cells Wolf Reik and M. Azim Surani

Comprehensive Catalog of Currently Documented Histone Modifications Yingming Zhao and Benjamin A. Garcia

Epigenetic Regulation of Chromatin States in Schizosaccharomyces pombe Robin C. Allshire and Karl Ekwall

Histone Variants and Epigenetics Steven Henikoff and M. Mitchell Smith

For additional articles in this collection, see http://cshperspectives.cshlp.org/cgi/collection/

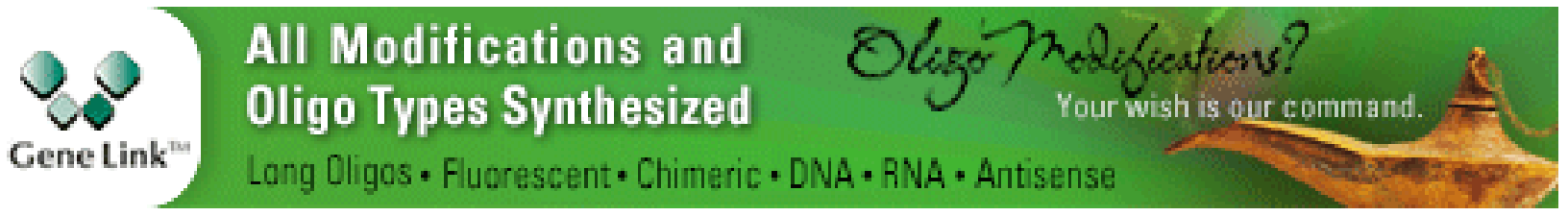

Copyright @ 2013 Cold Spring Harbor Laboratory Press; all rights reserved 
For additional articles in this collection, see http://cshperspectives.cshlp.org/cgi/collection/

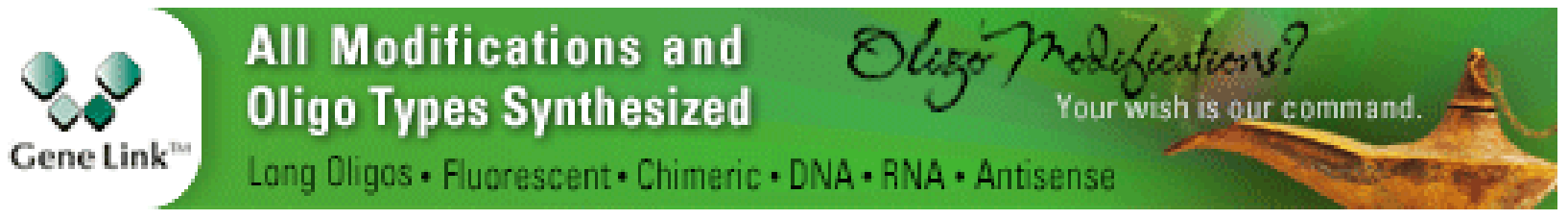

Copyright @ 2013 Cold Spring Harbor Laboratory Press; all rights reserved 